\section{Collapse episodes and remediation of subsidiary dam under construction of cut-off walls}

Lingwei Zheng PhD

Postdoctoral Researcher, Ningbo Institute of Technology, Zhejiang University, Ningbo, China; Research Center of Coastal and Urban Geotechnical Engineering, Zhejiang University, Hangzhou, China (Orcid:0000-0003-0559-7339)

\author{
Xinyu Xie PhD \\ Professor, Research Center of Coastal and Urban Geotechnical \\ Engineering, Zhejiang University, Hangzhou, China (corresponding author: \\ xinyu@nit.zju.edu.cn) (Orcid:0000-0001-8582-0857)
}

The main problems faced with earth dams relate to leakage, landslides and cracking, which are in turn related to seepage under and through dams. The construction of the Huangbizhuang reservoir began in 1958, and impounding started in 1960. The main purpose of the Huangbizhuang reservoir is flood control, while secondary uses are irrigation, fish farming, electricity generation and water supply. Many problems have occurred for more than $\mathbf{4 0}$ years of its operation. The construction of a seepage cut-off wall for the subsidiary dam began in March 1999. Seven dam collapses occurred during the construction of the cut-off walls. In this research study, the geological conditions of the site are considered, especially during the construction of the joint section of the cut-off wall ( $\sim 120 \mathrm{~m}$ long) where most of the collapses occurred. The methods for remediating the subsidiary dam of this reservoir are analysed and compared. Details of the collapses are described, and causes and improvement projects are proposed. Finally, suggestions regarding the construction of cut-off walls under such complex conditions are presented.

\section{Notation}

C cement content per cubic metre of concrete

$D_{15} \quad$ particle size from a particle-size distribution plot for which 15\% of particles are finer by weight

$D_{50} \quad$ particle size from a particle-size distribution plot for which 50\% of particles are finer by weight

$D_{85} \quad$ particle size from a particle-size distribution plot for which $85 \%$ of particles are finer by weight

$H \quad$ bearing head of the cut-off wall

$k \quad$ coefficient of permeability

$T \quad$ required anti-corrosion life

$t \quad$ thickness of the cut-off wall

$\alpha \quad$ volume of water seeping through per kilogramme of cement in the concrete wall when the strength of the concrete decreases to $50 \%$

\section{Introduction}

Many dams and reservoirs were built in the 1950s and 1960s in China. At that time, technology and financial support were limited; thus, most of the dams built during this period were not adequately designed for flood prevention and were of poor quality. These dams would not meet the requirements of the current national standards and are considered to be potentially hazardous. The main problems with earth dams relate to leakage, landslides, cracking and even collapse, which are in turn related to seepage under and through the dams.

Episodes of dam collapse have occurred due to seepage problems (Dong et al., 2016), internal erosion (Fell et al., 2003; Pailing et al., 2016; Sedghi-Asl et al., 2015) or poor quality of the foundation (Petaccia et al., 2016). Kociánová et al. (2016) analysed the influence factors of materials, technology of implementation, number and distribution of boreholes by the damage to the dam, the amount of leakages and its composition, which was detected by a ground-penetrating radar survey. $\mathrm{Hu}$ and $\mathrm{Ma}$ (2016) conducted a case study on foundation seepage problems encountered at an earth dam, Pipasi dam, over the last 55 years with various remediation efforts. The cause of the past seepage problems within the dam foundation is Neogene conglomerate outcrops in both abutments, which is overlaid by the relatively thin Quaternary deposit in the riverbed. The worst case is the collapse of an entire dam. Therefore, improvements are required to reduce the probability of failure by reducing the seepage and risk of internal erosion. Composite geomembrane and a concrete cut-off wall are used jointly to control seepage of the Xixiayuan dam, located on the Yellow River in China (Dong et al., 2016). Temperatures and water levels were measured in boreholes, reservoir water and leakage points. An interconnection test using salty water tracer was performed between the borehole and the leakage point. Chemical grouting (Drochytka and Magdaléna, 2017) was adopted as one of the repair options for remediation of earth dams relating to leaks and loss of stability. Low-pressure permeation grouting (Park and Oh, 2018) was adopted to remediate the deteriorated central core layers of five ageing dams and minimise the risk of hydraulic fracturing, without requiring a reduction in the reservoir water level.

According to statistical evidence from the Ministry of Water Resources of China, in 1999, approximately 34, 40 and $42 \%$ of large, medium and small reservoirs, respectively, were at risk of collapse. The dangerous condition of these dams and reservoirs results in low-efficiency reservoirs and, more importantly, 
threatens people living downstream. The main problems with earth dams relate to leakage, landslides and cracking, which in turn lead to seepage under and through the dams. Determining how to repair these hazardous earth dams has become an imperative for the authorities responsible for the reservoirs.

The Huangbizhuang reservoir, located on the Hutuohe River, $30 \mathrm{~km}$ upstream of Shijiazhuang city, is the capital city of Hebei Province and an important, large (size A) reservoir. The main purpose of the Huangbizhuang reservoir is flood control, while secondary uses are irrigation, fish farming, electricity generation and water supply. Construction of the reservoir began in 1958, and impounding began in 1960. The design water level is $127.6 \mathrm{~m}$ above sea level, with a normal operating water level of $120.0 \mathrm{~m}$. The principal structural elements are the main dam, the subsidiary dam, the gravity dam and other ancillary structures, including the primary spillway, auxiliary spillway, aqueduct and power plant (Figure 1). The main dam is a homogeneous earth structure constructed of mainly silty clay and is $30.7 \mathrm{~m}$ high and $1843 \mathrm{~m}$ long.

The dam collapsed seven times during the construction of the cut-off walls. Other severe problems, such as cracks in the impermeable upstream blanket and continuous seepage of the dam, also occurred. This paper describes the details of the collapses and analyses the causes and improvement plans for the dam. Suggestions regarding the construction of cut-off walls for such complex conditions are presented.

\section{Situation of and methods for improving the subsidiary dam}

\subsection{Situation of the subsidiary dam}

The subsidiary dam is also a homogeneous earth structure and is $19.2 \mathrm{~m}$ high and $6907 \cdot 3 \mathrm{~m}$ long. The crest and the base are 5 and $161.55 \mathrm{~m}$ wide, respectively. The elevation of the dam crest is $129 \cdot 2 \mathrm{~m}$ above sea level. There are berms on both the upstream and downstream slopes. Many problems have occurred during its more than 40 years of operation. The three main problems that exist are as follows.

(a) Poor construction quality of the dam. Cracks were present throughout the dam crest, but of the greatest concern were two or three rows of parallel cracks that had joined together and become continuous. The width of the cracks ranged from 2 to $4 \mathrm{~cm}$, and the greatest crack depth was up to $1.8 \mathrm{~m}$.

(b) Cracks in the impermeable upstream blanket of the dam were also severe. The impermeable upstream blanket was used as the horizontal seepage cut-off for the subsidiary dam. The severe cracking of the impermeable upstream blanket was evident from cracks and localised slumping collapses of the blanket that were found during inspections after routine drawdown of the reservoir.

(c) Continuous seepage breakthrough occurred at the downstream face of the dam. Many pressure relief holes ( $\sim 30 \mathrm{~m}$ deep) and barrel drains within the downstream face of the dam were blocked. The exit hydraulic

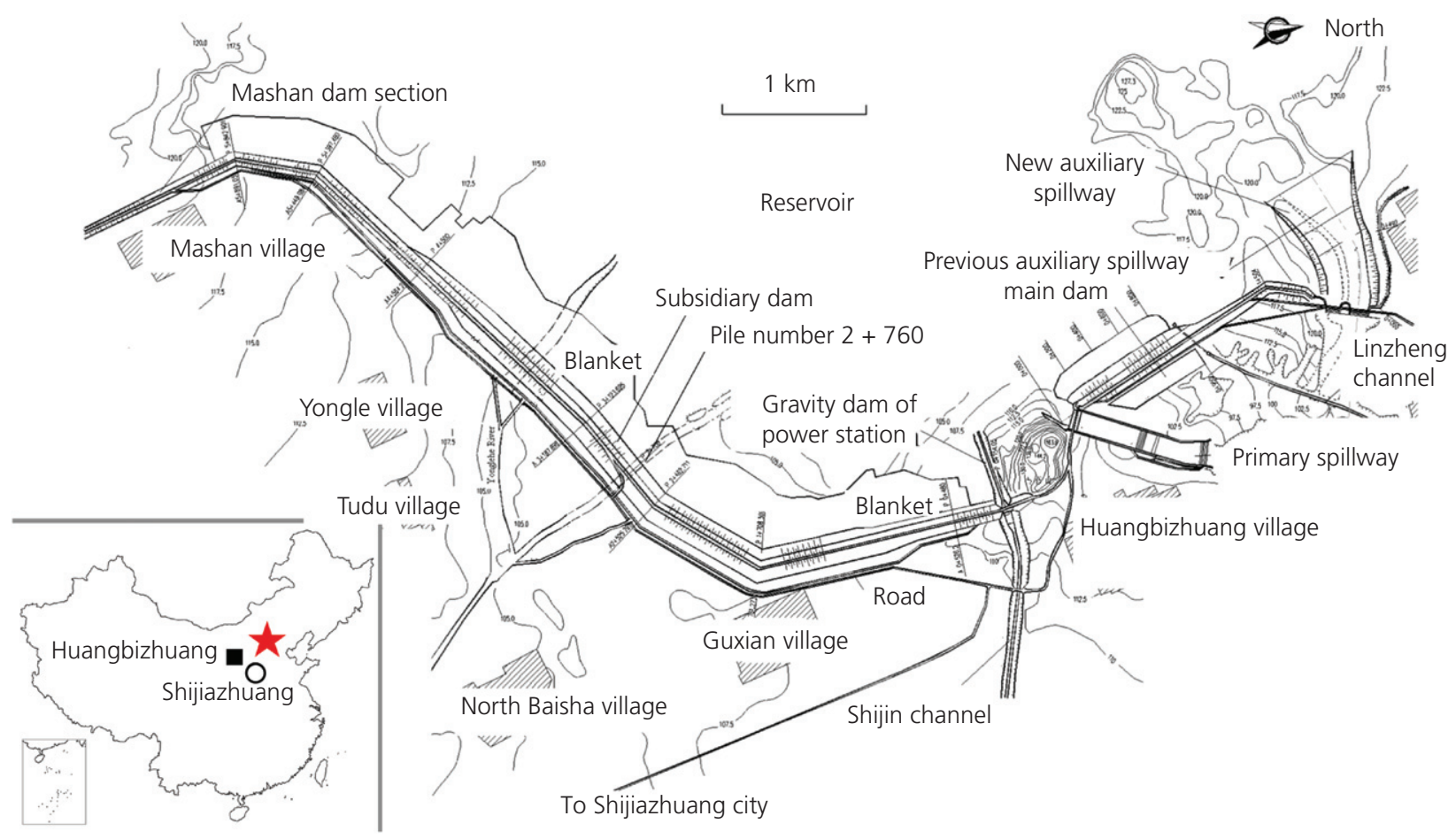

Figure 1. Plan view of the Huangbizhuang reservoir 
gradients of some sections at the downstream face of the dam were excessive when the water levels were high (Qi, 1995). Exit gradients from the monitoring results in some sections at the downstream face of the dam at the probable maximum flood (PMF) water level of $126 \cdot 8 \mathrm{~m}$ are shown in Table 1.

Some exit gradients exceed the specified allowable gradient, which is considerably lower than conventional thinking would imply in gap-graded granular soils (Skempton and Brogan, 1994). Such high exit hydraulic gradients could lead to instability and result in soil erosion at the downstream face of the dam. Dam failure would be catastrophic for Shijiazhuang city as well as for a railway, two oil fields and many other structures. After discussions and feasibility studies, a total investment of US\$151 billion was allocated to repair the Huangbizhuang Reservoir dam. This effort became the largest remedial work project of a high-risk reservoir in China. More than $75 \%$ of this investment was allocated to the construction of a cut-off wall in the subsidiary dam.

The subsidiary dam is founded on Pleistocene alluvium with a maximum thickness of approximately $70 \mathrm{~m}$ over bedrock. The alluvium consists of five main layers of silty clay, sand, gravel, cobbles and silty clay with gravel from top to bottom. The bedrock is seriously weathered, with erosion loss and a faulted tectonic zone.

The dam consists of mainly saturated silty clay with some sandy clay. The first layer of silty clay beneath the dam is similar to that of the dam body, is distributed continuously under the dam, and has a thickness of 4-6 m. The second layer of sand is divided into three types - that is, silty fine, medium and coarse sand, all of which are grey-yellow in

Table 1. Exit hydraulic gradients at downstream sections of the subsidiary dam

\begin{tabular}{|cc|} 
Section & Exit gradient \\
\hline $0+480$ & $0 \cdot 63$ \\
$1+080$ & $0 \cdot 29$ \\
$3+808$ & $0 \cdot 72$ \\
$5+170$ & $0 \cdot 37$ \\
$5+300$ & $0 \cdot 09$ \\
\hline
\end{tabular}

colour, wet and have a loose to medium relative density. The gravel layer is not continuous. The cobble content of the cobble layer ranges from 60 to $70 \%$ and is in some places up to $80 \%$ where grain sizes range from 2 to $8 \mathrm{~cm}$, with a maximum grain size of approximately $40 \mathrm{~cm}$.

As the gravel is not continuous, the sand layer is in direct contact with the cobble layer along approximately half the length of the dam. According to the particle-size distribution curves, the ratios of the particle sizes between both of these layers greatly exceed the specified requirements (Lambe and Whitman, 1969) shown in Table 2. Furthermore, the hydraulic gradient between both layers is considerably larger than the allowable value. Under such a high hydraulic gradient, sand could easily pass through the cobble layer and flow into the pressure relief holes. This sand would eventually block the pressure relief holes and loosen the sand layer, resulting in differential deformation and cracking of the blanket.

In the stratum under the subsidiary dam, there are central leakage zones, for which the coefficient of permeability $k$ ranged from 130 to $160 \mathrm{~m} / \mathrm{d}$ and reached up to $450 \mathrm{~m} / \mathrm{d}$ in certain locations. There is good connectivity between the cobble layer and bedrock in certain sections where soluble siliceous limestone and marble have dissolved. This good connectivity also resulted in zones of very high seepage in the bedrock. The lowest alluvium layer of red clay with gravel is relatively impervious, but this layer is not continuous along the dam and in certain locations comes into direct contact with the high-seepage zones in the bedrock. The average size diameter varies considerably, and there is a significant range in particle sizes in the cobble layer. This layer, which extends to a great depth, was the greatest cause of slurry leakage during the construction of the cut-off walls.

\subsection{Comparison of improvement methods}

On the basis of the problems with the subsidiary dam, several methods for improving the dam body and foundation are compared and evaluated. These methods are divided into two types: vertical and horizontal seepage cut-off methods. There are four types of vertical cut-off schemes based on the positions of the cut-off walls: vertical cut-off at the dam crest, vertical cut-off at the dam slope, vertical cut-off at the dam toe and combined vertical cut-offs at the dam crest and toe. The

Table 2. Filter-to-soil grain-size ratios for the soils beneath the dam

\begin{tabular}{|c|c|c|c|}
\hline Item & $D_{15}$ filter $/ D_{85}$ soil & $D_{50}$ filter $/ D_{50}$ soil & $D_{15}$ filter $/ D_{15}$ soil \\
\hline Cobble-clayey sand & $139 \cdot 5$ & 925 & 363 \\
\hline Cobble-fine sand & $30 \cdot 3$ & 247 & $108 \cdot 7$ \\
\hline Cobble-medium sand & 11 & $129 \cdot 5$ & $97 \cdot 9$ \\
\hline Cobble-coarse sand & $5 \cdot 9$ & $75 \cdot 5$ & $45 \cdot 5$ \\
\hline Cobble-gravel & 0.45 & $15 \cdot 7$ & $29 \cdot 4$ \\
\hline Requirement & $<5$ & $<25$ & $4-20$ \\
\hline
\end{tabular}


suggested scheme for a possible solution to the subsidiary dam problem is a vertical concrete cut-off wall at the dam crest.

A horizontal cut-off scheme was previously used in the subsidiary dam. Three horizontal cut-off improving schemes are considered: $(a)$ thickening the blanket and weighting at the downstream side, $(b)$ filling clay in the blanket and sealing it by itself and (c) laying geo-membrane on the blanket.

The advantages of horizontal cut-off schemes are a lower initial investment and a smaller influence on the volume of water leakage, which affects agricultural irrigation and drinking water of the downstream side. The disadvantages of these schemes are the additional difficulties in construction administration, a durability problem (the lifetime of the horizontal cut-off is shorter than that of the vertical cut-off) and a greater influence on flood control during construction, resulting in a smaller benefit to the reservoir (the water level of the reservoir must be dropped under the dead water level during construction, which has a negative effect on water storage and flood control).

The disadvantages of a vertical concrete cut-off wall at the dam crest are the higher initial investment, longer construction time and greater influence on the downstream environment. The advantages are the higher reliability and durability of the project, ease of construction administration and smaller influence on the adjustment of flood control during construction.

After discussions and comparisons of the schemes, the selected scheme was a vertical concrete cut-off wall at the dam crest as well as a shorter high-pressure grouted cut-off wall for the sand soil foundation. The cracks in the dam were treated by backfilling after digging the cracked part. This approach can also enable a construction platform of sufficient width. The cut-off walls connect with the above concrete parapet wall, which becomes a full vertical cut-off system from the top to the bedrock. This approach was anticipated to solve the subsidiary dam problem.

The anti-seepage style was changed to a vertical cut-off system instead of a horizontal system. Seepage through the dangerous sections was to be cut off, and the risk of cracks in the blanket and dam body was to be avoided.

\subsection{Design of the cut-off wall}

The length of the cut-off wall of the dam was determined by geological conditions and applications. Determination of the elevation of the cut-off wall must consider the following aspects. (a) The purpose of constructing a cut-off wall is to solve the problems of seepage-induced failure of the base and downstream of the dam and cut-off horizontal cracks of the dam. (b) Combining the treatment of the cracks at the dam crest, the excavation depth of the dam crest is no less than $1.5 \mathrm{~m}$. (c) The cut-off wall requires construction platforms that are approximately $18 \mathrm{~m}$ long; over $2 \mathrm{~m}$ of the dam crest must be excavated to achieve this platform width. (d) To reduce the influence on water storage and flood control of the reservoir, the top elevation of the cut-off wall should not be too low.

According to the manner and condition of construction, the thickness of the cut-off wall was preliminarily determined to be $80 \mathrm{~cm}$, and the anti-corrosion life was checked. Considering the importance of the project, the anti-corrosion life is generally 100-200 years, and the empirical formula (MOHURD, 2002) is

1. $t=\sqrt{\frac{T k H}{\alpha C}}$

where $t$ is the thickness of the cut-off wall (m) (here, with a value of $0.8 \mathrm{~m}) ; k$ is the permeability coefficient of the cut-off wall (m/a); $T$ is the required anti-corrosion life (years); $H$ is the bearing head of the cut-off wall (m); $\alpha$ is the volume of water seeping through per kilogramme of cement in the concrete wall when the strength of the concrete decreases to $50 \%\left(\mathrm{~m}^{3} / \mathrm{kg}\right)$, with $\alpha=1.54 \mathrm{~m}^{3} / \mathrm{kg}$ for typical concrete; and $C$ is the cement content per cubic metre of concrete $\left(C=300 \mathrm{~kg} / \mathrm{m}^{3}\right)$.

\subsection{Details of the vertical cut-off walls}

According to the different conditions of the soil layers, the cut-off wall consisted of three forms.

(a) The section between stations $0+840 \cdot 0$ and $5+700 \cdot 0$ was a concrete cut-off wall, which is $4860 \mathrm{~m}$ long and $80 \mathrm{~cm}$ thick. The advantage of this type of cut-off wall is the larger depth of the wall, while the disadvantages are its higher cost and longer construction time.

(b) The section between stations $0+120 \cdot 5$ and $0+840 \cdot 0$ was a high-pressure wall grouted by a sprinkler head rotating within a circle, which is $583.0 \mathrm{~m}$ long and $60 \mathrm{~cm}$ thick. The advantages of grouting are the shorter construction time and lower cost, while the disadvantage is the limited construction depth

(c) The section between stations $6+440 \cdot 0$ and $6+720 \cdot 0$ was a high-pressure wall grouted by the sprinkler head rotating within an arc, which is $280.0 \mathrm{~m}$ long and $60 \mathrm{~cm}$ thick.

The platform for constructing the cut-off wall was at an elevation of $127 \mathrm{~m}$. The concrete of the wall beyond the elevation of $125.5 \mathrm{~m}$ was cast in sheeted brackets in a trench between the elevations of 125.5 and $127.5 \mathrm{~m}$. This wall is concrete parapet above an elevation of $127.5 \mathrm{~m}$. The maximum depth of the cut-off wall was up to $70.0 \mathrm{~m}$ from the elevation of $127.5 \mathrm{~m}$. The central line of the cut-off wall was located upstream $2.9 \mathrm{~m}$ away from the central line of the subsidiary dam. The depth of the cut-off wall inserted in the rock varied with the weathering grades of the rock: $1.0 \mathrm{~m}$ for slightly weathered rock, $1.5 \mathrm{~m}$ for seriously weathered rock and $2.0 \mathrm{~m}$ 
for fully weathered rock. The depth of the high-pressure grouting walls inserted in the rock was $0.5 \mathrm{~m}$.

A layer of red clay with gravel exists above the bedrock between stations $2+960 \cdot 0$ and $3+630 \cdot 0$, with a maximum thickness of $25 \cdot 2 \mathrm{~m}$. The depth of the cut-off wall in this layer was $2 \cdot 0 \mathrm{~m}$.

The material used for the cut-off wall was C10 normal concrete, which has a design compressive strength of $17 \cdot 0 \mathrm{MPa}$ and an anti-seepage grade of S8. The ratio of the elastic modulus to the compressive strength is not more than $1.75 \times 10^{4}$. The design compressive strength of the concrete for high-pressure grouting walls is $3.0 \mathrm{MPa}$ in the clay layers and $5.0 \mathrm{MPa}$ in the sand layers. The design coefficient of permeability of the walls is $9 \times 10^{-6} \mathrm{~cm} / \mathrm{s}$.

The total length of the cut-off wall was $5723.0 \mathrm{~m}$, and the wall area was $2.645 \times 10^{5} \mathrm{~m}^{2}$. This represented was the largest cut-off wall project in China. The construction had to stop during winters and flood seasons to ensure the safety of the unfinished trenches. A cross-section of the cut-off wall at the position of pile number $2+760$ is shown in Figure 2, which also contains the profile of the dam and the geological profile.

Piezometers were installed to monitor the effectiveness of the cut-off wall; some typical water levels before and after the cut-off wall construction are shown in Table 3. The statistical table of the water level from piezometers in sections shows that the water level in all sections declined significantly, from the cut-off wall at the start of construction (March 1999) to the end of construction (July 2003). The cut-off wall had played an important role in preventing seepage.

\section{Collapses during construction of the cut-off walls and remediation}

\subsection{Details of the vertical cut-off walls}

The construction of the seepage cut-off wall of the subsidiary dam began in March 1999. The dam collapsed seven times from October 1999 to November 2002. Six of the collapses occurred at a length of approximately $300 \mathrm{~m}$ between stations $\mathrm{A} 4+026$ and $\mathrm{A} 4+360$, while the fifth collapse occurred at $\mathrm{A} 2+824$ to $\mathrm{A} 2+861$. The last five collapses are shown in Figures 3 and 4 , and all collapses are described in Table 4. The range of every collapse is approximated as a circle around the construction spot (Figure 3). As shown by the cross-section of the collapses along the dam and soil layers (Figure 4), the subsidiary dam was identified as the most dangerous structure affecting the Huangbizhuang reservoir. The common characteristic of the collapses was that serious leakage of slurry occurred first, after which various measures were used to stop the leakage; however, these measures failed, and a collapse occurred. For remediation of a small-area collapse, the region of the collapse was removed and then backfilled to a relatively intact condition. For remediation of a large-area collapse, the expanded scope excavation of the collapsed region was adopted with vibroflotation reinforcement treatment.

\subsection{Causes of collapse}

\subsubsection{Complex geological and hydrological conditions}

(a) Dissolution of the developed bedrock. The bedrock of this section is mainly composed of marble and secondarily composed of marble and limestone interlayer. There is serious erosion on the surface of the marble and some cavities caused by karst erosion or fault. According to the results of the geological survey, among

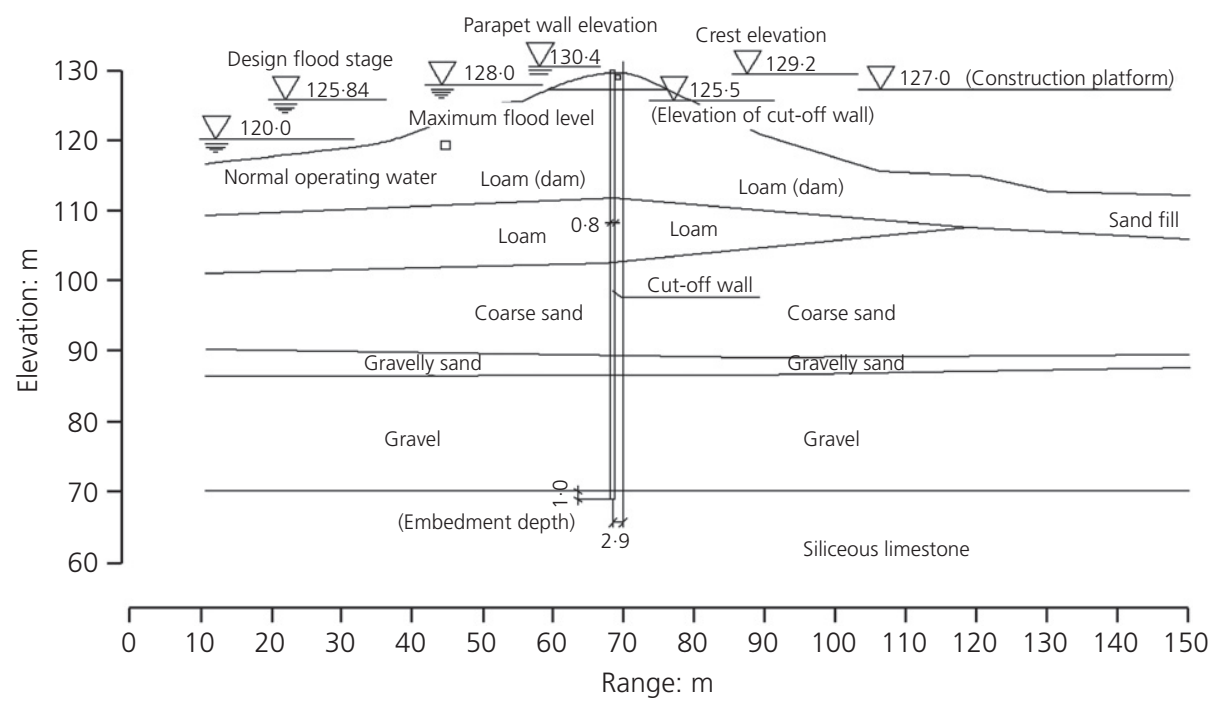

Figure 2. Cross-section of the cut-off wall section (pile number $2+760$ ) 
Table 3. Water level of a part of piezometers before and after cut-off wall construction

\begin{tabular}{|c|c|c|c|c|c|c|c|}
\hline Pile number & & $2+308 m$ & $2+608 m$ & $3+809 m$ & $4+408 m$ & $4+408 m$ & $5+088 \mathrm{~m}$ \\
\hline Reservoir level & Time/piezometer number & 044 & 059 & 074 & 084 & 088 & 098 \\
\hline \multirow[t]{3}{*}{114} & 5 August 1998 & $100 \cdot 97$ & $101 \cdot 83$ & $105 \cdot 55$ & $107 \cdot 97$ & $108 \cdot 47$ & $111 \cdot 18$ \\
\hline & 15 January 2002 & $94 \cdot 38$ & $96 \cdot 17$ & $100 \cdot 35$ & $102 \cdot 75$ & $103 \cdot 40$ & $104 \cdot 78$ \\
\hline & 5 September 2003 & $92 \cdot 05$ & 93.04 & $96 \cdot 01$ & $98 \cdot 36$ & 98.90 & $102 \cdot 14$ \\
\hline Variation & & 8.92 & $8 \cdot 79$ & $9 \cdot 54$ & $9 \cdot 61$ & $9 \cdot 57$ & $9 \cdot 04$ \\
\hline \multirow[t]{3}{*}{116} & 20 April 1998 & $102 \cdot 12$ & $103 \cdot 06$ & $106 \cdot 09$ & $108 \cdot 36$ & $108 \cdot 74$ & $111 \cdot 56$ \\
\hline & 10 September 2000 & 98.96 & 99.99 & $104 \cdot 69$ & $107 \cdot 75$ & $108 \cdot 27$ & $111 \cdot 36$ \\
\hline & 15 October 2003 & $92 \cdot 08$ & $93 \cdot 16$ & $96 \cdot 08$ & $98 \cdot 62$ & 99.04 & $102 \cdot 07$ \\
\hline Variation & & $10 \cdot 04$ & $9 \cdot 90$ & $10 \cdot 01$ & $9 \cdot 24$ & $9 \cdot 70$ & $9 \cdot 47$ \\
\hline \multirow{3}{*}{117} & 30 March 1998 & $102 \cdot 35$ & $103 \cdot 28$ & $106 \cdot 17$ & $108 \cdot 46$ & $108 \cdot 84$ & 111.76 \\
\hline & 20 December 2000 & $98 \cdot 19$ & $100 \cdot 42$ & $105 \cdot 62$ & $108 \cdot 12$ & $108 \cdot 60$ & $111 \cdot 43$ \\
\hline & 30 November 2003 & $92 \cdot 00$ & $93 \cdot 28$ & $96 \cdot 25$ & 98.90 & $99 \cdot 31$ & $102 \cdot 06$ \\
\hline Variation & & $10 \cdot 35$ & $10 \cdot 00$ & $9 \cdot 92$ & $9 \cdot 56$ & $9 \cdot 53$ & $9 \cdot 7$ \\
\hline
\end{tabular}

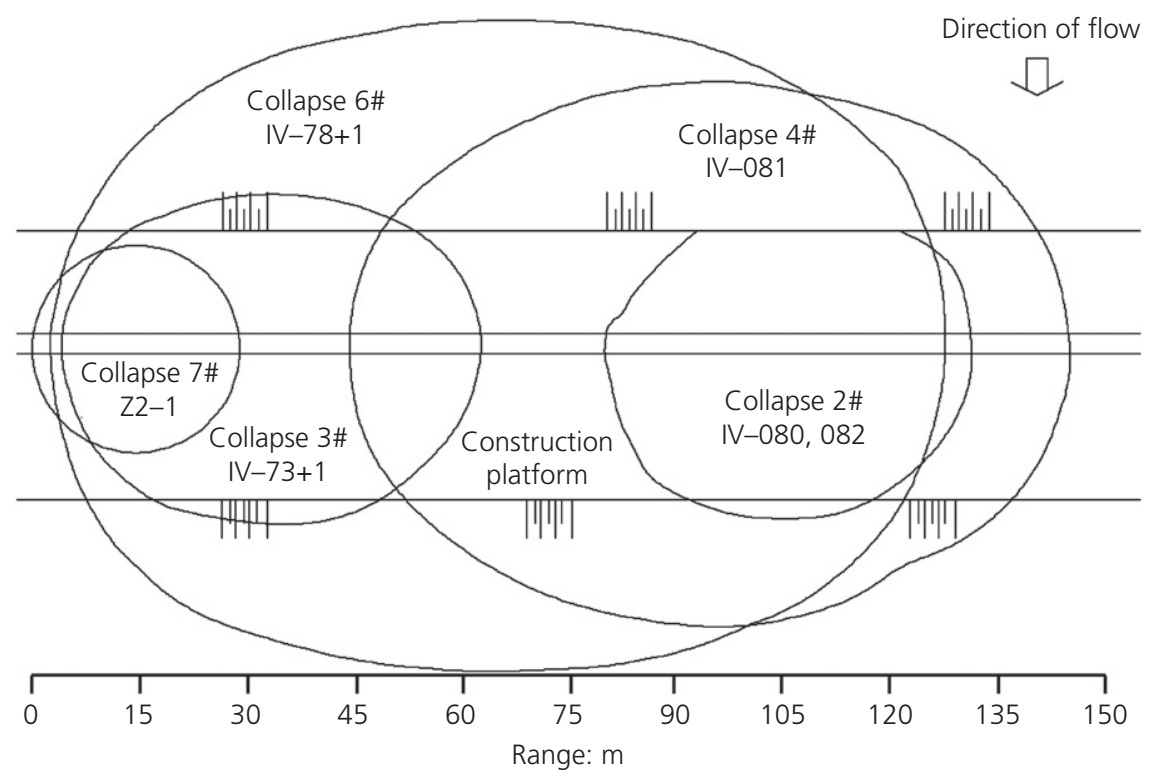

Figure 3. Plan view of the dam collapses

56 inspection boreholes, up to $28 \cdot 5 \%$ had karst erosion and $4.6 \%$ had faults. These results indicate that dissolution of the bedrock had developed in the stratum.

(b) Quick seepage zones in the stratum. There are cavities under the cobble layer due to erosion loss of the bedrock. The maximum seepage velocity is up to $143 \mathrm{~m} / \mathrm{d}$. Slurry and material for stopping the leakage was found in the cavities after the leakages of the cement slurry. Several collapses occurred after constructing the depth of bedrock. Thus, there were areas of quick seepage in the cobble layer, the zone connecting the cobble layer and bedrock, the zone connecting the clay with the gravel layer and bedrock, and part of the bedrock. These quick seepage areas might be the main cause of the leakage of the cement slurry and resulted in the loss of fine grains of the sand layer and others, which eventually led to the collapse of the dam. (c) Possible unstable stratum. The foundation under the dam consists of five layers of soils (from top to bottom, silty clay, sand, gravel, cobble and clay with gravel). The dam body, silty clay and sand layer are all regarded as soft soils. The shear strength of these layers will decrease after they are marinated in slurry for a long time. This reduction in shear strength may cause the trench to collapse. According to geological surveys, no changes in the cobble layer occurred after the collapse of the dam. Thus, the leakage of the slurry mainly occurred in the sand and silty clay layers.

(d) Poor seepage conditions in the construction joint section. The construction joint section became narrower, making the velocity of the seepage higher. Collapse number 6 occurred in the joint section and was the most severe. During the construction of the cut-off wall in the quick seepage area, the slurry leaked rapidly and combined with 


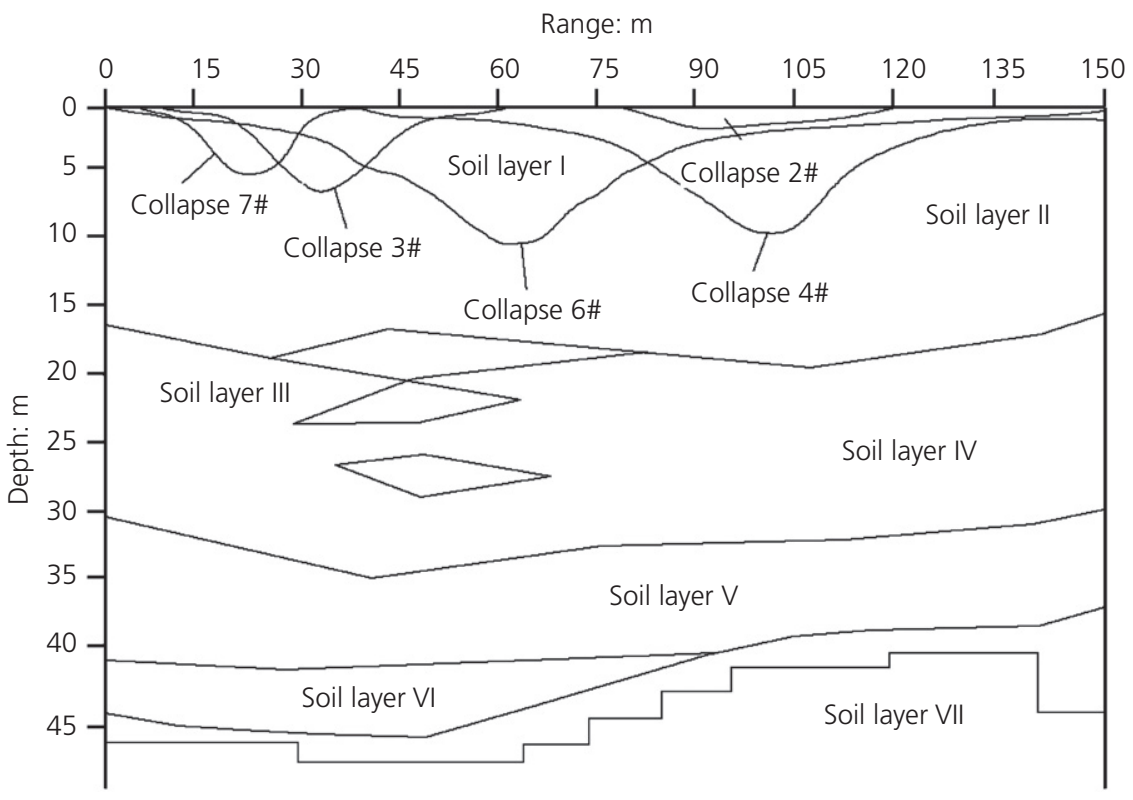

Figure 4. Cross-section of the collapses along the dam and soil layers

Table 4. Details of the dam collapses

\begin{tabular}{|c|c|c|c|c|c|c|}
\hline Number & Date & $\begin{array}{c}\text { Central station } \\
\text { number }\end{array}$ & $\begin{array}{l}\text { Dimension: } \\
\mathbf{m}\end{array}$ & $\begin{array}{l}\text { Influence range: } \\
\text { m }\end{array}$ & $\begin{array}{l}\text { Maximum subsidence } \\
\text { of dam: } m\end{array}$ & $\begin{array}{l}\text { Collapse volume } \\
\text { estimated: } \mathrm{m}^{3}\end{array}$ \\
\hline 1 & 22 October 1999 & $4+316 \cdot 3$ & $30.5 \times 22.5$ & $83.5 \times 33 \cdot 2$ & $5 \cdot 2$ & 732 \\
\hline 2 & 22 May 2000 & $4+130 \cdot 7$ & $40 \cdot 0 \times 5 \cdot 0$ & $100.0 \times 16.0$ & $5 \cdot 8$ & - \\
\hline 3 & 3 September 2000 & $4+062 \cdot 7$ & $10.5 \times 10.3$ & $50.8 \times 31.5$ & $7 \cdot 3$ & 700 \\
\hline 4 & 1 May 2001 & $4+126 \cdot 7$ & $34.8 \times 30.6$ & $96 \cdot 8 \times 66 \cdot 9$ & $8 \cdot 8$ & 2500 \\
\hline 5 (twin) & 5 October 2001 & $\begin{array}{l}2+848 \\
2+861\end{array}$ & $\begin{array}{c}13.3 \times 15 \cdot 5 \\
9.0 \times 6.0\end{array}$ & $7.5 \times 4.0$ & $\begin{array}{l}3 \cdot 5-3 \cdot 0 \\
3 \cdot 0-4 \cdot 0\end{array}$ & - \\
\hline 6 & 4 March 2002 & $4+088 \cdot 7$ & $46.2 \times 53.5$ & $127 \times 79 \cdot 5$ & $12 \cdot 1$ & 3900 \\
\hline 7 & 11 November 2002 & $4+054 \cdot 5$ & $5.4 \times 4.7$ & $49.9 \times 57.0$ & $5 \cdot 5$ & 320 \\
\hline
\end{tabular}

finer grains in the unstable layers. The traditional measures for stopping leakage were not available at the time.

\subsubsection{Construction manner unsuitable for the complex geological conditions}

Percussive drilling was used to construct the trench. However, this construction technique may be problematic as it caused vibrations during construction, destroyed the consolidated soil layers, deformed the ground and overturned the trench.

Bentonite slurry was used to support the trench during the cut-off wall construction. There was more than a $20 \mathrm{~m}$ distance between the top of the slurry and the groundwater level. The unit weight of slurry was larger than that of the water, forming a fairly high pressure difference. When percussive drilling reached the quick seepage layers, a large amount of the bentonite slurry leaked under such a high pressure. This leakage resulted in a negative pressure in the trench and caused the trench to overturn and the leakage of finer grains in the unstable layers.
The measures and material used for stopping the leakage are not effective for severe conditions. An excessive amount of time was taken up to construct the trenches. For example, construction of trench IV76+1 began on 24 August 2001 but was not completed by the end of November, and construction had to stop for winter. During the 3 month winter period, the soil backfilled into the trench. The stability of the slurry worsened after it was mixed with the backfilled soil, and its supporting effect on the trench decreased.

\section{Suggestions and conclusions}

The collapse accidents that occurred during the construction of the cut-off wall of the subsidiary dam of the Huangbizhuang reservoir resulted in an extra cost of approximately 70 million Yuan. The remedial work on the dam was completed in July 2003. Data from nearly 7 years of operation of the reservoir and the field observation results (Qi, 2009) indicate that the cut-off wall meets the anti-seepage requirement of the subsidiary dam. The following conclusions may be drawn from the practical project study. 
(a) The geological and hydrological conditions of the site are very complex. Cut-off walls are difficult to construct successfully in this type of site. More comprehensive geological survey is needed for such an important project. Dissolution of the bedrock developed, and the quick seepage zones in the stratum led to the leakage of a large amount of sand and finer grains of other layers. Then, hollows began to appear, causing the collapse that occurred in the dam.

(b) More attention should be paid to the construction scheme so that the construction technology can be adapted for such a complex site. Grab bucket and percussive drilling are not suitable for use in constructing such a trench. A long period of trench construction reduces the stability of the trench. The use of a large-diameter sleeve support is effective for trench construction in quick seepage areas.

(c) During construction in the possible leakage zones, the changes in the slurry face should be observed more carefully, and all types of material for stopping leakage must be prepared, including clay, cement, graded gravels, sacked clay, sacked cement and clay balls. Once the slurry begins to leak, more slurry should be supplied immediately. If the leakage is very fast, the appropriate material must be backfilled at once. If the leakage of the slurry cannot be stopped after several attempts, backfilling and grouting must be considered.

(d) Concrete cut-off walls are widely applied as an anti-seepage measure in dams. Several other earth dams in China are experiencing similar conditions. More effective construction technology for cut-off walls under such complex geological and hydrological conditions must be developed.

\section{Acknowledgement}

The authors acknowledge Hongbo Cao, the former deputy director general of Huangbizhuang Reservoir Administration Office, who provided a portion of the measured data, design materials and construction documents related to the project. This support is gratefully acknowledged.

\section{REFERENCES}

Dong H, Chen J and Li X (2016) Delineation of leakage pathways in an earth and rockfill dam using multi-tracer tests. Engineering Geology 212: 136-145.

Drochytka R and Magdaléna K (2017) Options for the remediation of embankment dams using suitable types of alternative raw materials. Construction and Building Materials 143: 649-658.

Fell R, Wan CF, Cyganiewicz J and Foster M (2003) Time for development of internal erosion and piping in embankment dams. Journal of Geotechnical and Geoenvironmental Engineering 129(4): 307-314.

$\mathrm{Hu} \mathrm{J}$ and Ma F (2016) Evaluation of remedial measures against foundation leakage problems of earth dams on pervious conglomerate strata: a case study. Bulletin of Engineering Geology and the Environment 75(4): 1519-1540.
Kociánová M, Drochytka R and Černý V (2016) Technology of remediation of embankment dams by optimal grout. Procedia Engineering 151: 257-264.

Lambe TW and Whitman RV (eds) (1969) Soil Mechanics. Massachusetts Institute of Technology, Cambridge, MA, USA.

MOHURD (Ministry of Housing and Urban-Rural Development PRC) (2002) GB 50069-2002: Structural design code for special structures of water supply and waste water engineering. China Architecture \& Building Press, Beijing, China.

Pailing CF, Jones DE and Worthington S (2016) Slurry trench cut-off wall and permeation grouting of Chapel House Embankment Dam, Cumbria. In Dams - Benefits and Disbenefits; Assets or Liabilities?: Proceedings of the 19th Biennial Conference of the British Dam Society (Pepper A (ed.)). ICE Publishing, London, UK, pp. 139-150.

Park D and Oh J (2018) Permeation grouting for remediation of dam cores. Engineering Geology 233: 63-75.

Petaccia G, Lai CG, Milazzo C and Natale L (2016) The collapse of the Sella Zerbino gravity dam. Engineering Geology 211: 39-49.

Qi JT (1995) Analysis on effect and measures of horizontal anti-seepage for the auxiliary dam of Huangbizhuang reservoir. Hebei Water Resource and Hydropower Technology 19(1): 48-51.

Qi JT (2009) Analysis on monitoring data of cut-off wall of auxiliary dam at Huangbizhuang reservoir. Dam and Safety 11(5): 25-28.

Sedghi-Asl M, Parvizi M, Armin M and Flores-Berrones R (2015) Internal erosion under spillway rested on an embankment dam. International Journal of Mining and Geo-Engineering 49(2): 269-279.

Skempton AW and Brogan JM (1994) Experiments on piping in sandy gravels. Géotechnique 44(3): 449-460, https://doi.org/10.1680/ geot.1994.44.3.449 